\title{
Galanin-like Peptide Ameliorates Obesity by Control of Food Intake and Energy Metabolism
}

\author{
Satoshi Hirako1, Fumiko Takenoya ${ }^{1,2}$, Haruaki Kageyama ${ }^{1,3}$, Nobuhiro Wada ${ }^{1}$, Mai Okabe ${ }^{4}$ and Seiji Shioda ${ }^{1 *}$ \\ ${ }^{1}$ Department of Anatomy, Showa University School of Medicine, Tokyo, Japan \\ ${ }^{2}$ Department of Exercise and Sports Physiology, Hoshi University School of Pharmacy and Pharmaceutical Science, Tokyo, Japan \\ ${ }^{3}$ Faculty of Health Care, Kiryu University, Gunma, Japan \\ ${ }^{4}$ Tokyo Shokuryo Dietitian Academy, Tokyo, Japan
}

\begin{abstract}
Galanin-like peptide (GALP) is a 60 amino acid neuropeptide that was first isolated from the porcine hypothalamus. It is produced in the hypothalamic arcuate nucleus by neurons that form networks with other neurons containing peptides involved in the control of feeding behavior. GALP plays an important role in the regulation of feeding, body weight and energy metabolism. Although the physiological actions of GALP are yet to be fully elucidated, it is possible, given the anti-obesity effect of GALP seen in relation to food intake and body weight loss in obese mice, that GALP could be applied clinically to combat obesity in humans. Here we summarize what is known about the regulation of energy metabolism by GALP, and describe results in animals that could possibly lead to the clinical use of GALP to treat obesity.
\end{abstract}

Keywords: GALP; Clinical implication; Energy metabolism; Antiobesity; Feeding regulation

\section{Introduction}

Metabolic syndrome is composed of a variety of diseases related to obesity, such as glucose intolerance, hyperinsulinemia, dyslipidemia, and hypertension [1-3]. The prevalence of metabolic syndrome is on the rise in many parts of the world, with the main causes of obesity being associated with overeating and lack of exercise [4]. In this context, the control of energy metabolism and regulation of food intake form key pillars in the treatment of metabolic syndrome.

Many neuropeptides in the hypothalamus are involved in modulating feeding behavior and energy homeostasis. It has been reported that the lateral hypothalamus ( $\mathrm{LH})$ is a feeding center, the ventromedial hypothalamus $(\mathrm{VMH})$ is a satiety center, and the arcuate nucleus (ARC) is an integrated center for feeding regulation $[5,6]$. A number of studies have demonstrated that appetite is regulated by many neuropeptides, and that takes place via a neural network linking these brain centers. Neuropeptide Y (NPY), melanin-concentrating hormone $(\mathrm{MCH})$, orexin, galanin, and agouti gene-related protein (AgRP) are typical orexigenic peptides, while $\alpha$-melanocyte stimulating hormone $(\alpha-\mathrm{MSH})$, corticotropin-releasing hormone (CRH), cocaine- and amphetamine-regulated transcript (CART), neuropeptide W (NPW) and galanin-like peptide (GALP) have been described as anorexigenic peptides [7-14]. Moreover, the levels of many neuropeptides are linked to the actions of leptin, in addition to which it has been shown that neurons containing feeding regulating neuropeptides interact with each other via synaptic inputs $[15,16]$. We previously reported on a number of functional analyses that clarified the actions of many feeding regulating peptides in the brain, among these being GALP [17-21].

In 1999, GALP was isolated from the porcine hypothalamus on the basis of its ability to bind to and activate galanin receptors in vitro [22]. GALP is a 60 amino acid peptide, where amino acids 9-21 are identical to the biologically active $\mathrm{N}$-terminal amino acids 1-13 of galanin (Figure 1). Recent studies demonstrated that GALP has physiological actions that are different from those of galanin. In addition to discussing the physiological actions of GALP, this review also summarizes results from studies in which GALP was administered intranasally (i.n.) to obese mice, thereby providing insights into how GALP might be used clinically to treat obesity in humans.

\section{Distribution of GALP and its Neuronal Network}

Some studies have demonstrated the localization and distribution of GALP neurons in the brains of rats and mice. In rodents, in situ hybridization histochemistry revealed that GALP mRNA is distributed in the periventricular regions of the ARC, in the median eminence, and in the pituitary gland [23-26]. Immunohistochemistry studies have shown that GALP-immunoreactive neuronal cell bodies are observed in the ARC and posterior pituitary gland [27]. Furthermore, GALPimmunoreactive fibers were distributed in the ARC, paraventricular nucleus (PVN), bed nucleus of the stria terminalis (BST), medial preoptic area (MPA), and lateral septal nucleus (LSV) [27].

GALP-containing neurons receive afferent inputs from NPYcontaining neurons in the ARC and from orexin-containing neurons in the LH $[17,18]$. Additionally, GALP-containing neurons project to orexin- and $\mathrm{MCH}$-containing neurons in the LH [19]. GALPcontaining neurons thus form neuronal networks with several feedingrelated peptide-containing neurons, and have also been shown to coexpress the leptin receptor, NPY Y1 receptor, orexin type 1 receptor and serotonin $5-\mathrm{HT}_{2 \mathrm{c}}$ receptor in rodents and monkey, which suggests that GALP neurons may be under the control of leptin, NPY, orexin and serotonin $[17,27,28]$. Leptin receptor immunoreactivity in particular was identified in more than $85 \%$ of GALP-containing neurons [27]. Further to this, we demonstrated that approximately $10 \%$ of GALP-

*Corresponding author: Seiji Shioda, Department of Anatomy, Showa University School of Medicine, 1-5-8 Hatanodai,Shinagawa-ku, Tokyo 142 8555, Japan, Tel: +81-3-3784-8104; Fax: +81-3-3784-8615; E-mail: shioda@med.showa-u.ac.jp

Received April 17, 2014; Accepted May 27, 2014; Published May 30, 2014

Citation: Hirako S, Takenoya F, Kageyama H, Wada N, Okabe M, et al. (2014) Galanin-like Peptide Ameliorates Obesity by Control of Food Intake and Energy Metabolism. Pharm Anal Acta 5: 297. doi:10.4172/2153-2435.1000297

Copyright: $\odot 2014$ Hirako S, et al. This is an open-access article distributed under the terms of the Creative Commons Attribution License, which permits unrestricted use, distribution, and reproduction in any medium, provided the original author and source are credited. 
Citation: Hirako S, Takenoya F, Kageyama H, Wada N, Okabe M, et al. (2014) Galanin-like Peptide Ameliorates Obesity by Control of Food Intake and Energy Metabolism. Pharm Anal Acta 5: 297. doi:10.4172/2153-2435.1000297

containing neurons co-express $\alpha-\mathrm{MSH}$ [18]. Taken together, these observations suggest that GALP-containing neurons are intimately connected to various feeding-related neuron types in the hypothalamus and are affected by leptin released from adipose tissues (Figure 2).

Receptor binding experiments suggested that the receptor for GALP is actually the galanin receptor (GALR), which has three known subtypes: GALR1, GALR2 and GALR3. In vitro studies showed that GALR3 has the highest affinity for GALP followed by GALR2 and then GALR1 [22,29]. Physiological studies in rats, however, demonstrated that the GALP receptor is not GALR. In this way, the central administration of a GALR2/3 agonist to rats had no effect on food intake and body weight [30]. In addition, the distribution of GALR and c-Fos expression in the brains of rats after the central administration of GALP is different [31]. Furthermore, the physiological effects of GALP did not disappear following the administration of GALP to GALR1 or GALR2 knock-out (KO) mice [32]. These results suggested that the GALP receptor may be GALR3, but the true identity of GALP receptors has not yet been established. Identification of GALP specific receptor is very important in order to understand the physiological functions of GALP.

\section{Regulation of GALP mRNA Expression}

In rats, the process of fasting reduces GALP mRNA expression and the number of neurons expressing GALP [27]. Further to this, the relationship between GALP and leptin levels has attracted attention due to the fact that the plasma leptin concentration is reduced in response to fasting. Leptin administration increased the number of GALP expressing cells in the brains of fasted rats compared to control fasted rats that were injected with saline [27]. Conversely, GALP mRNA levels are reduced in leptin-deficient $o b / o b$ mice, in leptin receptor-deficient $d b / d b$ mice, and in Zucker obese rats compared to their wild type counterparts $[16,33]$. Interestingly, it was shown that GALP mRNA expression in $o b / o b$ mice can be restored by leptin administration, which suggests that GALP-expressing neurons are a directly regulated target of leptin.

A previous study also reported that GALP expression is regulated by insulin [34]. While GALP mRNA expression in streptozotocininduced diabetic rats was lower than that of vehicle-treated rats, levels could be restored to normal by administering leptin or insulin. These results suggest that GALP expression is regulated by leptin and insulin.

\section{Anti-obesity Effect of GALP}

GALP was initially described as an orexigenic neuropeptide given that administration of GALP into the brain induces food intake for the first hour thereafter in rats [35-38]. We previously reported that c-Fos immunoreactivity is increased in orexin-immunoreactive neurons in the LH after the central administration of GALP [39]. Furthermore, antiorexin IgG markedly inhibits GALP-induced food intake. Kuramochi et al. [37] reported that the intracerebroventricular (i.c.v.) injection of GALP increases c-Fos expression in NPY-containing neurons in the dorsomedial hypothalamic nucleus (DMH) [37]. Food intake is similarly increased by GALP administered in this way. In addition, the hyperphagic effect of GALP can be suppressed by inhibiting the action of NPY. However, this orexigenic action of GALP in rats is only a short-term effect. In the 24 hours following the i.c.v. administration of 1.6 or $5 \mathrm{nmol}$ GALP, body weight significantly decreased about 5 or $25 \mathrm{~g}$ compared with the vehicle treatment $[38,40]$.

In contrast with that seen in rats, an orexigenic action of GALP is not seen following its administration to mice, where a decreased food intake is seen after two hours and both food intake and body weight are suppressed in the 24 hours following GALP administration $[30,32,41,42]$. Specifically, in $1.2 \mathrm{nmol}$ GALP i.c.v administration, it is the minimum dose in previous reports, body weight was significantly decreased [42]. In $o b / o b$ mice, body weight and food intake decreased continuously following chronic GALP administration for 14 days [43].

It has also been reported that GALP regulates energy metabolism (Table 1). The central administration of GALP produces a dose-dependent increase in core body temperature which lasts for 6-8 $\mathrm{h}$ after treatment [38]. We found increases in heart rate, oxygen consumption and core body temperature but not skin temperature. GALP-induced thermogenesis is perfectly inhibited by administration of the cyclooxygenase (COX) inhibitor in both our and Lawrence's experiments $[38,44]$. These studies suggesting that this effect could be dependent on the action of prostaglandin $[38,44]$. Intracerebroventriclar injection of GALP induced c-Fos expression in astrocytes in the periventricular zone of the third ventricle. In addition, we examined COX1, COX2 and prostaglandin $\mathrm{E}_{2}$ synthetases (PGESs) mRNA expression after the in primary cultured astrocytes treated with GALP. Both COX2 and cytosolic PGES expression was found to be significantly increased by this treatment, which suggests that GALP evokes thermogenesis via a prostaglandin $\mathrm{E}(2)$-mediated pathway in astrocytes of the central nervous system [44]. The hyperthermia response due to GALP administration is similar to that achieved by the i.c.v. administration of interleukin (IL)-1 [45]. To this end, GALP administration increases IL- $1 \alpha / \beta$ production in microglia and macrophages. As a consequence of this, in IL- $1 \alpha / \beta$, IL- $1 \beta$, or IL-1 type1 receptor-deficient mice, food intake reduction, weight loss and thermogenesis are suppressed in response to the i.c.v. administration of GALP. Thus, it is considered that the thermogenesis and food intake reduction effects of GALP are mediated by IL- 1 production and

10

20

30

40

50

60

Human APAHRGRGGWTLNSAGYLLG PVLHL PQMGDQD GKRETALEILDLWKAIDGL PYS HP PQPS

Monkey APAHQGRGGWTLNSAGYLLGPVLHLPQMGDQDRKRETALE ILDLWKA IDGLPYSHPLQPS

Pig APVHRGRGGWT LNSAGYLLGPVLHPPSRAEGGGKGKTALGILDLWKAIDGLPYPQSQLAS

Rat APAHRGRGGWT LNSAGYLLGPVLH LSSKANQGRKTD SALE ILDLWKAIDGL PYSRS PRMT

Mouse

APAHRGRGGWTLNSAGYLLGPVLPVS SKADQGRKRDSALEI LDLWKI IDGLPYSHS PRMT

The gray area indicates amino acids sequences of galanin that are identical between species.

Figure 1: Sequence comparison of galanin-like peptide (GALP) from five different species. 


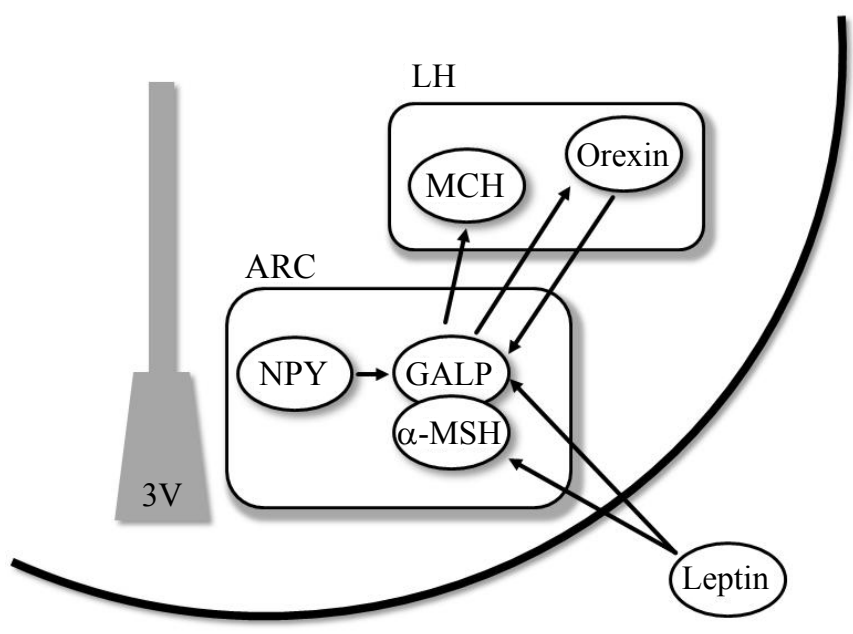

Adiposetissue

GALP neurons send outputs to orexin- or melanin-concentrating hormone$(\mathrm{MCH})$ containing neurons in the lateral hypothalamus (LH) and receive inputs from orexin neurons in the $\mathrm{LH}$ and neuropeptide $\mathrm{Y}$ neurons in arcuate nucleus (ARC). GALP-containing neurons also co-localize with alpha-melanin stimulating hormone (alpha-MSH)-immunopositivity. $3 \mathrm{~V}=$ third ventricle.

Figure 2: Schematic diagram of possible neuronal network involving GALP and other feeding-related peptide-containing neurons in the hypothalamus.

\begin{tabular}{|l|l|}
\hline Effect & Reference \\
\hline Increase of food intake (rat, short-term) & $\begin{array}{l}\text { Matsumoto et al. [36] } \\
\text { Lawrence et al. [38] } \\
\text { Lawrence et al. [35] } \\
\text { Kuramochi et al. [37] }\end{array}$ \\
\hline Decrease of food intake (rat, long-term) & $\begin{array}{l}\text { Lawrence et al. [38] } \\
\text { Krasnow et al. [41] }\end{array}$ \\
\hline Decrease of food intake and body weight (mouse) & $\begin{array}{l}\text { Hansen et al. [43] } \\
\text { Krasnow et al. [41] } \\
\text { Krasnow et al. [32] } \\
\text { Kauffman et al. [42] } \\
\text { Man et al. [45] }\end{array}$ \\
\hline Increase in heat population & $\begin{array}{l}\text { Lawrence et al. [38] } \\
\text { Hansen et al. [43] } \\
\text { Man et al. [45] }\end{array}$ \\
\hline Increase in oxygen consumption & Rich et al. [40] \\
\hline Enhancement of glucose and lipid metabolism & Ito et al. [46] \\
\hline
\end{tabular}

Table 1: Effect of GALP for energy metabolism.

the IL-1 type1 receptor [45]. In addition, chronic administration of GALP to $o b / o b$ mice increases the uncoupling protein (UCP) 1 gene and protein expression in brown adipose tissue (BAT). As BAT is a thermogenic organ innervated by the sympathetic nervous system, it is suggested that the enhanced energy metabolism induced by GALP takes place via sympathetic activation [43].

Further to the above, we reported that a change occurs in the respiratory exchange ratio (RER) in response to the i.c.v. administration of GALP. The RER indicates the amount of oxygen an organism consumes compared to the amount of carbohydrate dioxide it produces, and forms an essential part of the evaluation of metabolic status. The oxidation of carbohydrate results in an RER of 1.0, compared with 0.7 for fat and 0.8 for protein. In non-exercising mice, the RER was reduced 2 hours after GALP administration and increased thereafter, suggesting that the GALP enhances glucose and lipid metabolism under these conditions [46]. We also examined the effect of GALP on gene expression in the liver and in skeletal muscle in relation to glucose and lipid metabolism. The gene expression of hepatic SREBP-1c, which regulates fatty acid synthesis, was reduced by GALP administration, whereas that of GLUT4, which mediates glucose uptake by muscle, was increased. These findings suggest that GALP improves lipid metabolism in the liver and increases glucose uptake by muscle.

Taken together, these findings could explain the anti-obesity effect of GALP.

\section{Possible Clinical Applications of GALP}

The use of physiologically active peptides as therapeutic agents may reduce patient compliance and quality of life when these agents are administered parenterally. The intranasal (i.n.) route of administration, however, offers distinct advantages as the nasal mucosa has a rich vascular supply (facilitating drug uptake), and the administration can be performed easily by the patient.

We have considered the i.n. route of administration as a method for the clinical delivery of GALP [47]. In this way, the rate of uptake of intravenous (i.v.-) or i.n.-administered radioactively iodinated GALP (I-GALP) into the brains of mice was measured. I-GALP uptake into the olfactory bulb was very high, and was also elevated in the hypothalamus and hippocampus compared with other brain areas. In this way, the incorporation efficiency of I-GALP via the i.n. route was more than five times that of the i.v. route. Next, we observed the uptake of I-GALP into peripheral tissues, where the i.v. route resulted in much higher I-GALP levels in the spleen than were found for the i.n. route.

Uptake of I-GALP into the brain after i.n. administration was inhibited by unlabeled GALP, which suggests that this route of drug delivery results in the efficient transfer of GALP to the brain without concomitant distribution to the peripheral tissues. Many peptidebased drugs are often administered via the i.n. route in conjunction with the absorption enhancer, cyclodextrin [48-50]. Cyclodextrin is a cyclic glucan that can form inclusion complexes with many substances. I-GALP uptake into the brain was increased threefold by the combined administration of cyclodextrin and I-GALP, a finding that was confirmed autoradiographically and morphologically. We also studied the effect of GALP on feeding behavior in $o b / o b$ mice following its administration via the i.n. route and found that food intake and body weight were both decreased. The same effect of GALP on body weight was found for diet-induced obesity (DIO) mice treated i.n with GALP (unpublished findings). As no change in the locomotor activity of these animals was observed, these findings suggest that the weight decrease induced by GALP occurred as a result of increased energy metabolism. The i.n. delivery method may as such be potentially useful to treat lifestyle-related diseases and obesity in humans.

\section{Conclusion}

We have summarized here many of the feeding- and energy metabolism-related functions of GALP. While the physiological mechanisms of GALP's actions are gradually being elucidated, the nature of its receptor is yet to be clarified and remains a key to discovering the widespread actions of this neuropeptide. Recent studies have shown that GALP enhances energy metabolism, and we have demonstrated its capacity to reduce obesity following its administration via the i.n. route. Further studies to reveal GALP's actions may result in it becoming a key player in the fight against obesity. 
Citation: Hirako S, Takenoya F, Kageyama H, Wada N, Okabe M, et al. (2014) Galanin-like Peptide Ameliorates Obesity by Control of Food Intake and Energy Metabolism. Pharm Anal Acta 5: 297. doi:10.4172/2153-2435.1000297

\section{References}

1. Wilson PW, D’Agostino RB, Sullivan L, Parise H, Kannel WB (2002) Overweight and obesity as determinants of cardiovascular risk: the Framingham experience. Arch Intern Med 162: 1867-1872.

2. Gotto AM Jr (1998) Triglyceride as a risk factor for coronary artery disease. Am J Cardiol 82: 22Q-25Q.

3. Meshkani R, Adeli K (2009) Hepatic insulin resistance, metabolic syndrome and cardiovascular disease. Clin Biochem 42: 1331-1346.

4. Alberti KG, Zimmet P, Shaw J (2006) Metabolic syndrome--a new world-wide definition. A Consensus Statement from the International Diabetes Federation. Diabet Med 23: 469-480.

5. Kageyama H, Takenoya F, Hirako S, Wada N, Kintaka Y, et al. (2012) Neuronal circuits involving neuropeptide $\mathrm{Y}$ in hypothalamic arcuate nucleus-mediated feeding regulation. Neuropeptides 46: 285-289.

6. Shioda S, Takenoya F, Yagi M, Wang L, Hori Y, et al. (2008) Neural networks of several novel neuropeptides involved in feeding regulation. Nutrition 24: 848 853.

7. Takenoya F, Kageyama H, Shiba K, Date Y, Nakazato M, et al. (2010) Neuropeptide W: a key player in the homeostatic regulation of feeding and energy metabolism? Ann N Y Acad Sci 1200: 162-169.

8. Takenoya F, Kageyama H, Hirako S, Ota E, Wada N, et al. (2012) Neuropeptide w. Front Endocrinol (Lausanne) 3: 171.

9. Kageyama H, Takenoya F, Shiba K, Shioda S (2010) Neuronal circuits involving ghrelin in the hypothalamus-mediated regulation of feeding. Neuropeptides 44 : 133-138.

10. Funahashi H, Takenoya F, Guan JL, Kageyama H, Yada T, et al. (2003) Hypothalamic neuronal networks and feeding-related peptides involved in the regulation of feeding. Anat Sci Int 78: 123-138.

11. Hondo M, Ishii M, Sakurai T (2008) The NPB/NPW neuropeptide system and its role in regulating energy homeostasis, pain, and emotion. Results Probl Cell Differ 46: 239-256.

12. Kageyama H, Takenoya F, Kita T, Hori T, Guan JL, et al. (2005) Galanin-like peptide in the brain: effects on feeding, energy metabolism and reproduction. Regul Pept 126: 21-26.

13. Shiba K, Kageyama H, Takenoya F, Shioda S (2010) Galanin-like peptide and the regulation of feeding behavior and energy metabolism. FEBS J 277: 50065013.

14. Shioda S, Kageyama H, Takenoya F, Shiba K (2011) Galanin-like peptide: a key player in the homeostatic regulation of feeding and energy metabolism? In J Obes (Lond) 35: 619-628.

15. Muroya S, Funahashi H, Yamanaka A, Kohno D, Uramura K, et al. (2004) Orexins (hypocretins) directly interact with neuropeptide $\mathrm{Y}, \mathrm{POMC}$ and glucose-responsive neurons to regulate $\mathrm{Ca} 2+$ signaling in a reciprocal manne to leptin: orexigenic neuronal pathways in the mediobasal hypothalamus. Eur $J$ Neurosci 19: 1524-1534.

16. Kumano S, Matsumoto H, Takatsu Y, Noguchi J, Kitada C, et al. (2003) Changes in hypothalamic expression levels of galanin-like peptide in rat and mouse models support that it is a leptin-target peptide. Endocrinology 144 2634-2643.

17. Takenoya F, Aihara K, Funahashi H, Matsumoto H, Ohtaki T, et al. (2003) Galanin-like peptide is target for regulation by orexin in the rat hypothalamus. Neurosci Lett 340: 209-212.

18. Takenoya F, Funahashi H, Matsumoto H, Ohtaki T, Katoh S, et al. (2002) Galanin-like peptide is co-localized with alpha-melanocyte stimulating hormone but not with neuropeptide $\mathrm{Y}$ in the rat brain. Neurosci Lett 331: 119-122.

19. Takenoya F, Hirayama M, Kageyama H, Funahashi H, Kita T, et al. (2005) Neuronal interactions between galanin-like-peptide- and orexin- or melaninconcentrating hormone-containing neurons. Regul Pept 126: 79-83.

20. Date $\mathrm{Y}$, Mondal MS, Kageyama H, Ghamari-Langroudi M, Takenoya F, et al (2010) Neuropeptide W: an anorectic peptide regulated by leptin and metabolic state. Endocrinology 151: 2200-2210.

21. Kageyama H, Kitamura Y, Hosono T, Kintaka Y, Seki M, et al. (2008) Visualization of ghrelin-producing neurons in the hypothalamic arcuate nucleus using ghrelin-EGFP transgenic mice. Regul Pept 145: 116-121.
22. Ohtaki T, Kumano S, Ishibashi Y, Ogi K, Matsui H, et al. (1999) Isolation and cDNA cloning of a novel galanin-like peptide (GALP) from porcine hypothalamus. J Biol Chem 274: 37041-37045.

23. Juréus A, Cunningham MJ, McClain ME, Clifton DK, Steiner RA (2000) Galaninlike peptide (GALP) is a target for regulation by leptin in the hypothalamus of the rat. Endocrinology 141: 2703-2706.

24. Kerr NC, Holmes FE, Wynick D (2000) Galanin-like peptide (GALP) is expressed in rat hypothalamus and pituitary, but not in DRG. Neuroreport 11 3909-3913.

25. Larm JA, Gundlach AL (2000) Galanin-like peptide (GALP) mRNA expression is restricted to arcuate nucleus of hypothalamus in adult male rat brain Neuroendocrinology 72: 67-71.

26. Shen J, Larm JA, Gundlach AL (2001) Galanin-like peptide mRNA in neura lobe of rat pituitary. Increased expression after osmotic stimulation suggests a role for galanin-like peptide in neuron-glial interactions and/or neurosecretion. Neuroendocrinology 73: 2-11.

27. Takatsu Y, Matsumoto H, Ohtaki T, Kumano S, Kitada C, et al. (2001) Distribution of galanin-like peptide in the rat brain. Endocrinology 142: 16261634

28. Cunningham MJ, Shahab M, Grove KL, Scarlett JM, Plant TM, et al. (2004) Galanin-like peptide as a possible link between metabolism and reproduction in the macaque. J Clin Endocrinol Metab 89: 1760-1766.

29. Lang R, Berger A, Santic R, Geisberger R, Hermann A, et al. (2005) Pharmacological and functional characterization of galanin-like peptide fragments as potent galanin receptor agonists. Neuropeptides 39: 179-184.

30. Man PS, Lawrence CB (2008) The effects of galanin-like peptide on energy balance, body temperature and brain activity in the mouse and rat are independent of the GALR2/3 receptor. J Neuroendocrinol 20: 128-137.

31. Fraley GS, Shimada I, Baumgartner JW, Clifton DK, Steiner RA (2003) Differential patterns of Fos induction in the hypothalamus of the rat following central injections of galanin-like peptide and galanin. Endocrinology 144: 11431146

32. Krasnow SM, Hohmann JG, Gragerov A, Clifton DK, Steiner RA (2004) Analysis of the contribution of galanin receptors 1 and 2 to the central actions of galanin-like peptide. Neuroendocrinology 79: 268-277.

33. Juréus A, Cunningham MJ, Li D, Johnson LL, Krasnow SM, et al. (2001) Distribution and regulation of galanin-like peptide (GALP) in the hypothalamus of the mouse. Endocrinology 142: 5140-5144.

34. Fraley GS, Scarlett JM, Shimada I, Teklemichael DN, Acohido BV, et al. (2004) Effects of diabetes and insulin on the expression of galanin-like peptide in the hypothalamus of the rat. Diabetes 53: 1237-1242.

35. Lawrence CB, Williams T, Luckman SM (2003) Intracerebroventricular galanin-like peptide induces different brain activation compared with galanin. Endocrinology 144: 3977-3984.

36. Matsumoto Y, Watanabe T, Adachi Y, Itoh T, Ohtaki T, et al. (2002) Galanin like peptide stimulates food intake in the rat. Neurosci Lett 322: 67-69.

37. Kuramochi M, Onaka T, Kohno D, Kato S, Yada T (2006) Galanin-like peptide stimulates food intake via activation of neuropeptide $Y$ neurons in the hypothalamic dorsomedial nucleus of the rat. Endocrinology 147: 1744-1752.

38. Lawrence CB, Baudoin FM, Luckman SM (2002) Centrally administered galanin-like peptide modifies food intake in the rat: a comparison with galanin. J Neuroendocrinol 14: 853-860.

39. Kageyama H, Kita T, Toshinai K, Guan JL, Date Y, et al. (2006) Galanin-like peptide promotes feeding behaviour via activation of orexinergic neurones in the rat lateral hypothalamus. J Neuroendocrinol 18: 33-41.

40. Rich N, Reyes P, Reap L, Goswami R, Fraley GS (2007) Sex differences in the effect of prepubertal GALP infusion on growth, metabolism and LH secretion. Physiol Behav 92: 814-823.

41. Krasnow SM, Fraley GS, Schuh SM, Baumgartner JW, Clifton DK, et al. (2003) A role for galanin-like peptide in the integration of feeding, body weight regulation, and reproduction in the mouse. Endocrinology 144: 813-822.

42. Kauffman AS, Buenzle J, Fraley GS, Rissman EF (2005) Effects of galanin-like peptide (GALP) on locomotion, reproduction, and body weight in female and male mice. Horm Behav 48: 141-151. 
Citation: Hirako S, Takenoya F, Kageyama H, Wada N, Okabe M, et al. (2014) Galanin-like Peptide Ameliorates Obesity by Control of Food Intake and Energy Metabolism. Pharm Anal Acta 5: 297. doi:10.4172/2153-2435.1000297

43. Hansen KR, Krasnow SM, Nolan MA, Fraley GS, Baumgartner JW, et al. (2003) Activation of the sympathetic nervous system by galanin-like peptide--a possible link between leptin and metabolism. Endocrinology 144: 4709-4717.

44. Kageyama H, Endo K, Osaka T, Watanabe J, Wang LH, et al. (2013) Galaninlike peptide (GALP) facilitates thermogenesis via synthesis of prostaglandin E2 by astrocytes in the periventricular zone of the third ventricle. $\mathrm{J} \mathrm{Mol} \mathrm{Neurosci}$ 50: $443-452$

45. Man PS, Lawrence CB (2008) Interleukin-1 mediates the anorexic and febrile actions of galanin-like Peptide. Endocrinology 149: 5791-5802.

46. Ito K, Kageyama H, Hirako S, Wang L, Takenoya F, et al. (2013) Interactive effect of galanin-like peptide (GALP) and spontaneous exercise on energy metabolism. Peptides 49: 109-116.
47. Nonaka N, Farr SA, Kageyama H, Shioda S, Banks WA (2008) Delivery of galanin-like peptide to the brain: targeting with intranasal delivery and cyclodextrins. J Pharmacol Exp Ther 325: 513-519.

48. Yu S, Zhao Y, Wu F, Zhang X, Lü W, et al. (2004) Nasal insulin delivery in the chitosan solution: in vitro and in vivo studies. Int J Pharm 281: 11-23.

49. Nonaka N, Farr SA, Nakamachi T, Morley JE, Nakamura M, et al. (2012) Intranasal administration of PACAP: uptake by brain and regional brain targeting with cyclodextrins. Peptides 36: 168-175.

50. Banks WA, During MJ, Niehoff ML (2004) Brain uptake of the glucagon-like peptide-1 antagonist exendin(9-39) after intranasal administration. J Pharmacol Exp Ther 309: 469-475. 